\title{
Impacts of the Québec carbon emissions trading scheme on plant-level performance and employment
}

\author{
Julien Hanoteau ${ }^{a, b}$ and David Talbot ${ }^{c}$ \\ ${ }^{a}$ KEDGE Business School, Marseille, France; ${ }^{b}$ Aix-Marseille School of Economics (AMSE), Marseille, France; ${ }^{c}$ Ecole Nationale \\ d'Administration Publique (ENAP), Québec, Canada
}

\begin{abstract}
In 2013, Québec implemented a greenhouse gas (GHG) emissions trading system (QC ETS), despite opposition from industry, which feared loss of competitiveness and warned about job destruction. This article assesses the impact of that carbon regulation on industrial facili-ties in Québec. Conditional difference-in-differences ordinary least squares regressions show that regulated plants reduced their GHG emissions by about $9.8 \%$, employment by about $6.8 \%$ and carbon intensity by about $3.7 \%$ more compared to non-regulated plants in the rest of Canada during the period 2013-2015. This suggests that facilities adapted to the new program by improving their technology, but first and foremost by scaling down their activ-ity, which raises questions about the ability of the QC ETS to induce enough environmental investment and innovation in industrial facilities. The results, in terms of employment effects, contrast with the findings of similar studies on the early stages of the European ETS and the British Columbia carbon tax scheme, and this information challenges the initial allocation scheme for permits, in particular, with a view to a green fiscal reform.
\end{abstract}

\section{KEYWORDS}

Environmental regulation; carbon market; employment; climate policy

\section{Introduction}

On December 15, 2011, the Government of Canada announced its withdrawal from the Kyoto Protocol [1]. At that time, Peter Kent, the Canadian Minister of Environment, justified the decision by citing the absence of the two biggest emitters China and the United States - from the agreement. He claimed that for Canada '[to] meet [its] targets under Kyoto for 2012 would be the equivalent of [...] removing every car, truck, ATV [all-terrain vehicle], tractor, ambulance, police car and vehicle of every kind from Canadian roads' [2]. Canada's lack of leadership on climate issues was widely criticized in the media. Despite the federal government's withdrawal, the province of Québec (Canada) decided to honor its commitments. On the same day as Canada's withdrawal from the protocol and with great ceremony, Québec's Minister of the Environment announced that the province was adopting new regulations to set up a carbon emissions trading system (ETS) based on the Western Climate Initiative (WCI)'s recommendations [3]. Implemented in 2013, the new capand-trade system aimed to cover almost $85 \%$ of Québec's emissions [4]. According to government authorities, this economic tool has several advantages. Notably, it offers emitters a variety of options for complying with the regulations and provides a reliable mechanism for achieving reduction targets [4]. Numerous social and environmental groups praised the provincial government for this initiative. Some businesses and industry representatives, however, were apprehensive about the regulations' impact on corporate competitiveness $[5,6]$, arguing that this would result in a carbon leakage (with the relocation of production and emissions outside Québec) and a cut in local industrial production. ${ }^{1}$

According to the Government of Québec, the first results of the province's carbon market are very encouraging [11]. From 2013 to 2018, Québec's emissions trading scheme (QC ETS) generated more than CAD $\$ 2.2$ billion. According to the government [11], industrial emitters in Québec reduced their emissions by almost $800,000 \mathrm{t} \mathrm{CO}_{2} \mathrm{e}$ between 2012 and 2014. The government considers these reductions a sign that the carbon market is working. However, the Sustainable Development Commissioner [12] provides a more nuanced view of QC ETS performance, noting that emitters had access to an abundance of emissions permits

CONTACT David Talbot David.Talbot@enap.ca E Ecole Nationale d'Administration Publique (ENAP), 55 boulevard Charest Est, Québec G1K 9E5, Canada 
during the first years of compliance (i.e. the supply was higher than the demand); if this worrisome situation persists, then in the long term the carbon market might not produce the desired effect on GHG emissions. This implies that government authorities did not adequately plan for, or that they underestimated, the way businesses would react to the new regulations. In this context, conducting studies to evaluate the regulations' actual impact on emitters' economic performance is of utmost importance. The Government of Québec wants to lower its GHG emissions, but it also wants to prevent carbon leakage and voluntary decreases in production [4]. The challenge is particularly important considering the limited opportunities for improvement in industrial processes (before 2030) and the technical constraints that, in particular, may limit the possibilities for converting fossil fuels [13]. Despite the importance of industry in Québec's carbon footprint (31.6\% in 2012), this sector reduced its emissions by $21 \%$ between 1990 and 2012 [13].

The long-term goal of the QC ETS is to stimulate innovation and to make the transition to a less carbon-dependent economy easier. There are a few studies on the effectiveness of markets that follow the WCI's norms [e.g. 14, 15], but these have not specifically examined the impact of the ETS on industrial emitters' economic and carbon performance. The majority of previous studies that tried to evaluate carbon market effectiveness looked at the European Union emissions trading scheme (EU ETS). These studies showed the EU ETS's negative effect on emitters' $\mathrm{CO}_{2}$ emissions [16]. In the case of French and German industrial facilities, the reductions observed during the second phase of the EU ETS, between 2008 and 2010, amounted to between $10 \%$ and $26 \%[16,17]$. At the same time, however, the reductions achieved during phase 1 - between 2005 and 2008 - were smaller, which raises questions about the impact that the design of the market had on its effectiveness. The results of studies examining carbon performance are relatively convergent. The results are more mixed when it comes to economic impact, particularly the market's effect on employment [16]. Contrary to what might have been expected when the carbon market was adopted, the majority of studies found no relationship between employment in regulated facilities and the implementation of the market [e.g. 8, 18, 19]. There is a noticeable exception: decreases in employment of up to $7 \%$ were observed for industrial facilities in France [20].
Studies have also investigated whether regulated plants in Europe have chosen between innovation (reducing the carbon intensity of production) or cutting their operations in order to meet their emissions reduction targets [21-23]. For the first two phases of the EU ETS, results tend to show that facilities, rather than cutting their operations, have innovated on and improved their processes, passing the costs on to their customers $[16,17$, 20]. What's more, Martin et al. [24, 25] underscored that the risks of reducing production are relatively low, given the perceived impact that future carbon prices will have on business decisions about where to maintain facilities. Although interesting, these results - because they are very context dependent - are difficult to translate to North American carbon markets. This is all the more true because business behavior and climate change strategies have historically differed from one continent to another [e.g. 26-28].

This study's goal is to evaluate the impact of the QC ETS on industrial facilities' economic and carbon performance. To this end, program evaluation methods are applied on a panel of plantlevel data on carbon emissions and employment from regulated facilities in Québec and from unregulated facilities in Québec and the rest of Canada. The context of this study is original and interesting as both regulated and unregulated facilities belong to the same country, thus facing the same market conditions in terms of overall commodity price, demand and supply. In addition, they are in the same range of size of emissions, and this latter characteristic is unique as previous studies, in the context of the European ETS for instance, compare regulated large emitters with unregulated small emitters, thus introducing a bias related to the size of emissions. The results, robust because they were obtained using alternatively conditional difference-in-differences (DiD) ordinary least squares (OLS) regressions and DiD matching estimator methods, challenge the economic effectiveness of the carbon market. Indeed, unlike their European counterparts, emitters in Québec seem to have preferred to reduce their production rather than improve their technology and production processes. This article has policy implications not only for the future of the $\mathrm{WCl}$, but also for Canadian climate change policies, because the Pan-Canadian Framework on Clean Growth and Climate Change calls for all Canadian provinces and territories to decide on their carbon pricing strategies in 2018. 
The rest of the article is organized as follows. First, strategic options to abating GHG emissions and the main characteristics of the QC ETS are presented. Second, the methodology and the main results are described. The closing section is devoted to a discussion of the results and their contribution in terms of policy implications and recommendations.

\section{Emissions trading system and compliance strategies}

Facilities whose GHG emissions are regulated through an ETS may comply by reducing their emissions and/or by using emissions permits. They will choose one and/or the other compliance strategy depending on two main variables: their emissions abatement cost function and the market price of the permits. A facility will cut its emissions as long as the permit price exceeds marginal abatement costs (MACs). ${ }^{2}$

There are multiple options for abating emissions and most are specific to the GHG, the sector and the product under consideration. They also depend on the production technology and the type of inputs, among other factors. In the manufacturing industry, these abatement options will lead facilities to transform production technology, to replace a dirty input with a cleaner one, to capture GHG emissions at the end of pipes (when technically feasible), or to scale down their activity. In the latter case, the MAC is the opportunity cost of a forgone production unit and the associated profits. ${ }^{3}$ During the first phases of the EU ETS, covering $\mathrm{CO}_{2}$ emissions only, facilities mainly used fuel switching (replacing coal with natural gas) for curbing emissions [31].

Significantly decreasing polluting emissions requires, most of the time, an initial capital investment - for example, in order to develop and install new production technology. This investment is likely to become profitable only in the long run, after several years of compliance with environmental regulations. For that reason, cutting emissions so as to comply with carbon pricing regulations is rather a long-run industrial investment project. It cannot be decided based on a static comparison between abatement costs and the current permit price observed on the spot market. Rather, firms' rational decisions must integrate the permit prices that will prevail during the entire lifespan of the industrial investment project. Firms must therefore anticipate the future prices of the permits [29]. For instance, if managers anticipate that the permit price will decrease and/or be too low in the future, this will decrease their incentive to invest today in a costly emissions reduction plan.

The price of GHG emissions permits is likely to vary in the future according to factors such as the level of economic activity, the price of energy, or the future evolution of environmental regulation. Acknowledging that firms are usually risk averse, if there is significant uncertainty about future permit prices - and firms can hardly tell the future - they will be reluctant to choose a compliance strategy requiring an initial capital investment [21]. Instead, they will prefer the option of scaling down their activity, as this does not need to involve sunk costs.

\section{Québec's emissions trading scheme}

The Government of Québec has given itself ambitious GHG reduction targets. It is aiming for a reduction of $20 \%$ by 2020 and $37.5 \%$ by 2030 [32]. To reach these goals, the government's preferred economic instrument is a system of capping and trading (C\&T) emissions permits within the framework of the WCl. This decision is explained in part by the flexibility that this mechanism provides to regulated businesses. It should also allow Québec to develop a more robust and less fossil-fueldependent economy [33]. Launched in 2013, the new market is one of the most ambitious ETSs in the world, because it covers almost $85 \%$ of emissions in Québec. By way of comparison, the EU ETS covers only about $45 \%$ of European emissions [12]. According to government estimates, by 2020 the carbon market will have made possible CAD \$3 billion worth of investments in the activities called for by the Climate Change Action Plan 2013-2020. The plan explains Québec's strategic approach to climate change. The programs that it funds include transportation electrification, financing green technology, and increasing the use of renewable energy sources. According to some estimates [34], this plan should create more than 43,000 full-time jobs (direct, indirect and induced jobs) and generate spinoffs of nearly CAD $\$ 3.5$ billion on gross domestic product (GDP). However, according to the results of an analysis conducted by the Ministry of Finance [13], achieving the 37.5\% reduction target by 2030 could have a negative impact in terms of GDP (- $0.09 \%)$ and employment $(-0.06 \%)$.

In 2008, the Government of Québec announced its intention to set up a carbon market. It took 5 
years of highly political negotiation and equivocation before it was able to adopt the new regulations, notably in order to create a framework for emitters' GHG emissions declarations and to harmonize the markets in Québec and California. The QC ETS includes three compliance periods. The first period (January 2013-December 2014) impacted 78 industrial facilities whose annual GHG emissions were equal to or greater than 25 kiloton-equivalents of $\mathrm{CO}_{2}{ }^{4}$ The number of facilities subject to the regulation increased considerably during the second period (January 2015-December 2017), to include fossil fuel distributors [32]. The annual cap on emissions for 2013 and 2014 was set at 23.30 million emissions permits. This cap increased in 2015 to 65.30 million emissions permits to take into account the newly regulated establishments and then decreased afterward to settle at 61.08 million emissions permits at the end of the second period. The third period (January 2018-December 2020) will end with a decrease in the cap by nearly $15 \%$ compared to 2015, settling at 55.74 million emissions permits [36]. To comply with the new ceiling, emitters must either decrease or compensate for their GHG emissions. To compensate for their emissions, they can purchase emissions permits (through auctions or by mutual agreement with the minister), take advantage of credits earned in exchange for early reductions achieved between 2008 and 2011 or use compensatory credits for GHG emissionreduction projects in industries that are not subject to compliance $[12,32]$.

The design of Québec's carbon market was influenced by the malfunctions observed in the EU ETS. To avoid the problems of tax evasion, price slumps and market manipulation, oversight mechanisms were integrated into the market. First, the Government of Québec decided to impose a minimum price for emissions permits sold at auction. In December 2013, the price floor was CAD \$10.75. This price floor is set to increase by $5 \%$ every year. This oversight mechanism decreases the volatility of carbon prices that had notably been observed in the European market [37-39]. It also sends a clear signal about the desired development of carbon prices in Québec [12]. To minimize potential market manipulations as well, Québec's regulations set a maximum on the quantity of emissions permits that can be purchased or held. For example, an emitter cannot acquire more than $25 \%$ of available permits during an auction. Moreover, bidders must comply with certain norms that require them to communicate information about their participation in the auction and their strategies for acquiring emissions permits, the goal being to prevent collusion and insider trading [12].

\section{Research design}

\section{Empirical methodology}

Following the empirical methodology of Fowlie et al. [40], variations in carbon regulations across Canadian provinces were exploited to assess the effect of the QC ETS on regulated facilities. To accomplish this, econometrically adjusted ex-post observed outcome variables (i.e. GHG emissions, employment, carbon intensity) were analyzed, of facilities with similar characteristics (size, industrial subsectors) across provinces in Canada. Using the program evaluation literature that has introduced the potential outcome framework, industrial facilities were considered as either participating in the QC ETS or not. Let the 'treatment' indicator $T_{i}=1$ if the facility $i$ is enrolled in the QC ETS (i.e. $i$ is 'treated'). Let $T_{i}=0$ if the facility $i$ is not regulated through its carbon emissions. The potential outcomes $Y_{i t}(1)$ and $Y_{i t}(0)$ are the average annual outcomes (emissions, employment or carbon intensity), conditional on participation and nonparticipation, respectively, at facility $i$ during the post-treatment period $(t=1)$ or the pre-treatment period $(t=0)$. The purpose is to estimate the sample average treatment effect on the treated (ATT):

$$
\alpha_{A T T}=E\left[Y_{i 1}(1)-Y_{i 1}(0) \mid T_{i}=1\right]
$$

where $\alpha_{A T}$ measures the average effect of the QC ETS on facility-level outcome variables observed at treated and non-treated facilities over several years prior to and after the launch of the program. Facility-level outcome variables collected from participants in the QC ETS during the post-treatment period enable the following estimate $E\left[Y_{i 1}(1) \mid T_{i}=\right.$ 1]. However, because $E\left[Y_{i 1}(0) \mid T_{i}=1\right]$ cannot be observed because of missing data, counterfactual outcomes were constructed using data on outcome variables collected on a 'comparison group' of non-participating facilities during periods $t=0$ and $t=1$.

\section{Conditional DiD OLS regression}

To estimate the effect of the QC ETS on facilitylevel outcome variables, a conditional DiD OLS regression model of the following form was used:

$$
\Delta Y_{i}=\beta X_{i}+\alpha T_{i}+\varepsilon_{i}
$$


where $\Delta Y_{i}=Y_{i t_{1}}-Y_{i t_{0}}$ is the difference in the outcome variable between the post-treatment and pre-treatment periods. $X_{i}$ is a vector of facility-level observable characteristics that are likely to vary across facilities (i.e. comparison and treatment groups), affect the evolution of facility-level outcome variables and are assumed to be orthogonal to the treatment status. These characteristics are facilities' historical levels (prior to the launch of the QC ETS) of the outcome (i.e. GHG emissions, employment or carbon intensity) and NAICS (North American Industry Classification System) industrial classification indicators (dummy variable). The coefficient $\alpha$ estimates the average effect of the QC ETS on changes in $Y_{i}$ over time and conditional on characteristics in $X_{i}$. $\varepsilon_{i}$ is an error term, independent of the treatment indicator $T_{i}$ and covariates in $X_{i}$, by assumption.

\section{DiD matching estimator}

This simple comparison of QC ETS facilities with non-ETS facilities, when controlling for observables, may result in bias if some of the changes in the outcome variables are attributed to the ETS, whereas in reality they are induced by some other systematic differences between ETS and non-ETS facilities. Such differences may result from the distribution of the vector of control variables $X_{i}$. To mitigate this bias, semi-parametric matching estimators [41] of the following form were used:

$$
\alpha_{D I D}=\frac{1}{N_{1}} \sum_{j \in \Pi_{1}}\left\{\left(Y_{j t_{1}}(1)-Y_{j t_{0}}(0)-\sum_{k \in \Pi_{0}} w_{j k}\left(Y_{k t_{1}}(0)-Y_{k t_{0}}(0)\right)\right)\right\}
$$

with $\Pi_{1}$ the set of facilities $j$ in the treatment group and $N_{1}$ their total number. $\Pi_{0}$ is the set of facilities $k$ in the comparison group. $w_{j k}$ is a weight placed on facility $k$ when building the counterfactual estimate for the treated facility $j$. The weight on control plants is based on a nearest neighbor matching (NNM) process, and it is stronger the more similar a control facility is to the treated facility. The similarity is based on the covariates in $X_{i}$ (i.e. historical emissions and NAICS industrial classification indicators). For sensitivity analysis, matching alternatively to the closest and the three closest neighbors was carried out. ${ }^{5}$ Because poor match quality could bias the results, and following Abadie and Imbens [43], the matching estimation is augmented with a regression-based adjustment (i.e. quadratic form, as the outcome variable is in log). In all the matching, an exact match on industry-specific historic emissions quartile indicators was specified. This is in order to account for potential unobserved determinants of facility-level emissions, such as production technology or demand for the product. Standard errors are estimated using the Abadie and Imbens [43] methodology.

\section{Data}

Industrial facilities in Québec covered by the ETS were considered the treatment group. These facilities have GHG emissions exceeding $25,000 \mathrm{t} \mathrm{CO}_{2} \mathrm{e}$ in 2012 or 2013. They pertain to 12 industrial sectors, as listed in Table 1.

The comparison group was considered to be industrial facilities from the same sectors and with the same characteristics (level of emissions in 2012 or 2013) from other provinces of Canada, excluding British Columbia (BC). This is because the Government of BC decided in 2007, and implemented in 2008, a carbon tax scheme (complemented with a revenue-neutral green fiscal reform), with a carbon price set initially at CAD $\$ 10 / t C_{2}$, and increasing gradually to reach $C A D$ $\$ 30 / \mathrm{tCO}_{2}$ in 2012 , the year of the program's full implementation. There were no such carbon pricing policies in other Canadian provinces at that time. ${ }^{6}$

Table 1. North American Industry Classification System (NAICS) sectors and number of facilities in the treatment and comparison groups.

\begin{tabular}{lrrr}
\hline \multirow{2}{*}{ Subsectors } & NAICS code & \multicolumn{2}{c}{ Number of facilities } \\
\cline { 3 - 4 } & & Treatment & group Comparison group \\
\hline Oil and gas extraction & 211 & 0 & 73 \\
Mining & 212 & 4 & 17 \\
Power generation & 221 & 2 & 57 \\
Food and beverage & 311,312 & 1 & 6 \\
Pulp, paper and wood & 321,322 & 9 & 15 \\
Refineries, oil and coal products & 324 & 2 & 13 \\
Chemicals and plastics & 325,326 & 5 & 31 \\
Glass, cement, lime and ceramics & 327 & 7 & 16 \\
Iron and steel & 3311,3312 & 5 & 8 \\
Non-ferrous metals and forging & $3313,3314,3315$ & 12 & 5 \\
Automobile & 336 & 0 & 1 \\
Miscellaneous & 339 & 0 & 245 \\
Total & & 47 & \\
\hline
\end{tabular}


Facility-level data on annual GHG emissions and employment during the period 2010-2015 were retrieved through Environment and Climate Change Canada [47], and the data are publicly available. This follows a modification in the Greenhouse Gas Reporting Program (GHGRP) which obliges all Canadian industrial facilities with emissions exceeding 50,000 t $\mathrm{CO}_{2}$ e to publicly disclose their emissions. ${ }^{7}$ The GHG emissions data set was accessed through the GHGRP. Data on facilitylevel characteristics (i.e. size, subsector) was accessed through the National Pollutant Release Inventory (NPRI). These data were linked using the ECCC's unique facility-level identifier, 'NPRI_ID'. Data on $\mathrm{GHG}$ emissions are given in $\mathrm{t} \mathrm{CO}_{2} \mathrm{e}$, and data on employment are given as number of employees.

\section{Variables and their specifications}

Changes in GHG emissions are defined as $\ln \left(G H G_{1}\right.$ $+1)-\ln \left(G H G_{0}+1\right)$, with $G H G_{0}$ and $G H G_{1}$ the average annual emissions during periods 0 and 1, respectively. For that purpose, GHG emissions are averaged in 3-year periods (2010-2012 or 2013-2015) or 2-year periods (2010-2011). Changes in facility-level employment follow the same construction, with $\ln \left(E M P_{1}+1\right)-\ln \left(E M P_{0}+\right.$ 1). Due to data limitations, it was not possible to investigate the effect of the QC ETS on carbon intensity, defined as GHG emissions divided by output. As an alternative, following Wagner et al. [48], a measure of carbon intensity in terms of employment (i.e. GHG emissions/employment) was used.

OLS estimates control for historical GHG emissions in 2010 (in log) and industrial classification indicator variables, which yields 51 facilities in the treatment group and 248 in the comparison group. Summary statistics are reported in Table 2.

Given that NNM procedures are more suitable for large samples, the relatively small size of the sample leads the authors, a priori, to be more confident in the results obtained from the conditional DiD OLS regressions, the main empirical model used here.

\section{Results}

To generate conditional DiD estimates, a simple linear regression framework was used. Changes in facility-level emissions (in log) were regressed on historical emissions (level in 2010, in log), industryfixed effects and the treatment indicator. Standard errors are clustered by province.

Changes in emissions between the periods 2010-2012 and 2013-2015, and also between 2010-2011 and 2013-2015, were considered to account for a potential anticipation effect. This effect means that facilities can anticipate the regulations and cut their emissions prior to their implementation [31], as early as 2012 in the present case. The results are presented in column (1) of Table 3.

It is noticeable that the DiD OLS estimated parameter for the treatment indicator is negative and statistically significant $(\alpha=-0.098 ; p$ value $<0.01)$. This parameter can be interpreted as the estimate of the average effect of the carbon regulation, in percentage terms [40]. It is about $9.8 \%$ here. This is equivalent to saying that regulated facilities in Québec, the treatment group, reduced their GHG emissions approximately $9.8 \%$ faster than non-regulated facilities in the rest of Canada, the comparison group. During the

Table 2. Summary statistics.

\begin{tabular}{|c|c|c|c|c|c|}
\hline Variables & Mean & SD & Min & Max & $\mathrm{N}$ \\
\hline \multicolumn{6}{|l|}{ Full sample } \\
\hline GHG emissions in $2010(1000$ t CO $2 \mathrm{e})$ & 739 & 1641 & 51 & 15,788 & 292 \\
\hline Employment in 2010 (number of employees) & 379 & 744 & 1 & 6500 & 292 \\
\hline$\Delta$ (GHG emissions) $\left(1000 \mathrm{t} \mathrm{CO}_{2} \mathrm{e}\right)$ & 12.84 & 268 & -1177 & 2519 & 292 \\
\hline$\Delta$ (employment) (number of employees) & 7.74 & 168 & -900 & 879 & 292 \\
\hline$\Delta$ (GHG/employment) & 0.54 & 12.27 & -82 & 121 & 292 \\
\hline \multicolumn{6}{|l|}{ ETS participants in Québec } \\
\hline GHG emissions in $2010(1000$ t CO $2 \mathrm{e})$ & 389 & 366 & 51 & 1258 & 47 \\
\hline Employment in 2010 (number of employees) & 493 & 406 & 1 & 1690 & 47 \\
\hline$\Delta\left(\mathrm{GHG}\right.$ emissions) $\left(1000 \mathrm{t} \mathrm{CO} \mathrm{C}_{2} \mathrm{e}\right)$ & -19.29 & 108 & -377 & 389 & 47 \\
\hline$\Delta$ (employment) (number of employees) & -35.67 & 122 & -508 & 354 & 47 \\
\hline$\Delta$ (GHG/employment) & -0.21 & 0.74 & -3.48 & 0.75 & 47 \\
\hline \multicolumn{6}{|l|}{ Non-regulated facilities, rest of Canada excluding $B C$} \\
\hline GHG emissions in $2010\left(1000\right.$ t $\left.\mathrm{CO}_{2} \mathrm{e}\right)$ & 806 & 1777 & 51 & 15788 & 245 \\
\hline Employment in 2010 (number of employees) & 357 & 791 & 1 & 6500 & 245 \\
\hline$\Delta$ (GHG emissions) $\left(1000 \mathrm{t} \mathrm{CO}_{2} \mathrm{e}\right)$ & 19.00 & 289 & -1177 & 2519 & 245 \\
\hline$\Delta$ (employment) (number of employees) & 16.07 & 174 & -900 & 879 & 245 \\
\hline$\Delta$ (GHG/employment) & 0.68 & 13.40 & -82 & 121 & 245 \\
\hline
\end{tabular}


example, facilities have cut their emissions by scaling down activity, but more importantly by reducing the carbon intensity of production [48]. In Germany, regulated facilities have essentially improved carbon intensity in order to abate emissions [17].

\section{Tests on different samples}

Seven observations were dropped due to missing employment data in order to harmonize the number of observations across the tests (47 regulated facilities in Québec and 245 in the control group). These seven observations correspond to four facilities in Québec and three in the treatment group. Of these four facilities in Québec, one was a heat and power generation station (Boralex, Kingsey Falls) emitting $\sim 132 \mathrm{kt}$ in 2010 , and it shut down in 2013. Another was a lime manufacturer (Graymont Inc., Joliette) emitting $\sim 78$ kt in 2010 and only $65 \mathrm{t}$ in 2015 (shut down). The third is a polystyrene foam manufacturer (OC Celfortec LPValleyfield) emitting $\sim 230 \mathrm{kt}$ per year on average in 2010-2012, and it cut its emissions by $37 \%$ during the period 2013-2015. This last facility had constant emissions over that period of $\sim 50 \mathrm{kt}$. The three facilities of the treatment group emitted between 65 and $80 \mathrm{kt}$ per year on average over the period 2010-2012, and their emissions rose by $7 \%$ (an assembly plant in the automobile sector), $40 \%$ (a gas plant) and $62 \%$ (a power plant), respectively, during the period 2013-2015. Given the small size of the sample, dropping these seven facilities may impact the results, which is why a series of tests were conducted to assess the effect of the regulations on changes in GHG emissions on an unrestricted sample including these seven facilities. Table 4 exhibits the results of these regressions. The estimates were also negative
( $\alpha=-0.485$, and $\alpha=-0.492$ ) and significant ( $p$ value $<0.01$ ), although greater in magnitude, and this confirms the previous results.

As a robustness check, regressions were run with an alternative comparison group, composed of small facilities in Québec. Data on facilities with GHG emissions lower than 25,000 t $\mathrm{CO}_{2} \mathrm{e}$ in 2012 or 2013, and from the same NAICS industrial sectors, were collected. Data on GHG emissions and employment originate from the Government of Québec. Due to missing data, the period covered is 2012-2015, with 2012 considered to be the pretreatment period, and 2013-2015 is the post-treatment period. The comparison and treatment groups have 60 and 58 facilities, respectively, and average emissions in 2012 of $19,593 \mathrm{t} \mathrm{CO}_{2} \mathrm{e}$ and $407,169 \mathrm{t} \mathrm{CO}_{2} \mathrm{e}$, which is more than 20 times greater for the treatment group than for the comparison group. The average variation of emissions was computed between the year 2012 and the period 2013-2015, and was found to be - $1.7 \mathrm{t}$ $\mathrm{CO}_{2} \mathrm{e}$ for the unregulated facilities and $-14 \mathrm{t} \mathrm{CO}_{2} \mathrm{e}$ for the regulated ones, 8 times more in absolute value. This difference in the variations of emissions is certainly related to the difference in the levels of emissions between the two groups.

Because the pre-treatment period (2012) is just prior to the launch of the program, a potential anticipation effect can introduce bias, and results must be considered cautiously. To mitigate this issue, at least partially, 2014 and 2015 were considered separately as post-treatment periods.

Results of DiD OLS regressions are presented in Table 5. The coefficients for all post-treatment periods were negative, and only significant for 2015. The estimated parameter for 2015 is - 2.577, meaning that regulated large emitters cut their emissions by $258 \%$ more than unregulated small emitters, in Québec. The magnitude of this effect,

Table 4. Robustness tests on a larger sample.

\begin{tabular}{|c|c|c|c|c|c|}
\hline & $\begin{array}{l}\text { DiD using OLS } \\
\text { (1) }\end{array}$ & $\begin{array}{l}\text { NNM1 } \\
(2)\end{array}$ & $\begin{array}{c}\text { NNM3 } \\
(3)\end{array}$ & $\begin{array}{l}\text { Regulated } \\
\text { facilities }\end{array}$ & $\begin{array}{l}\text { Control } \\
\text { group }\end{array}$ \\
\hline \multicolumn{6}{|c|}{ Dependent variable is $\Delta / n$ (GHG emissions) } \\
\hline 2010-2012/2013-2015 & $\begin{array}{l}-0.485^{* * *} \\
(0.102) \\
{[0.001]}\end{array}$ & $\begin{array}{l}-0.419^{*} \\
(0.233) \\
{[0.073]}\end{array}$ & $\begin{array}{l}-0.391^{*} \\
(0.229) \\
{[0.088]}\end{array}$ & 51 & 248 \\
\hline 2010-2011/2013-2015 & $\begin{array}{l}-0.492^{* * *} \\
(0.010) \\
{[0.001]}\end{array}$ & $\begin{array}{l}-0.439^{*} \\
(0.235) \\
{[0.062]}\end{array}$ & $\begin{array}{l}-0.400 * \\
(0.230) \\
{[0.082]}\end{array}$ & 51 & 248 \\
\hline \multicolumn{6}{|c|}{$\begin{array}{l}\text { GHG emissions are averaged over 3-year periods (2010-2012 or 2013-2015) or 2-year periods } \\
\text { (2010-2011). Emissions differences between two periods } 0 \text { and } 1 \text { are defined as } \ln (\mathrm{GHG} 1+1)- \\
\text { In(GHG0+1). The OLS estimates control for the historical level of the dependent variable in } 2010 \text { (in } \\
\text { log) and NAICS code indicator variables, with standard errors clustered by province. }\end{array}$} \\
\hline \multicolumn{6}{|c|}{$\begin{array}{l}\text { NNM: Nearest neighbor matching estimator. The closest neighbor (NNM1) or the three closest neighbors } \\
\text { (NNM3) were matched with quadratic bias adjustment. The NNM model matches the historical level of } \\
\text { the dependent variable and NAICS code indicators and exactly for industry-specific quartile indicators } \\
\text { of the dependent variable. Standard errors are Abadie-Imbens robust. }\end{array}$} \\
\hline \multicolumn{6}{|c|}{$\begin{array}{l}* * * \text { significant at the } 1 \% \text { level; } * * \text { significant at the } 5 \% \text { level; } * \text { significant at the } 10 \% \text { level. Standard } \\
\text { errors are reported in parentheses, and } p \text { values are given in square brackets. }\end{array}$} \\
\hline
\end{tabular}


Table 5. DiD using OLS with small facilities in Québec as comparison group.

DiD using OLS Regulated facilities Control group

\begin{tabular}{llll}
\hline Dependent variable is & $\Delta / n$ (GHG emissions) & & \\
$2012 / 2013-2015$ & -0.510 & 58 & 60 \\
& $(0.501)$ & & \\
& {$[0.311]$} & 58 & 60 \\
$2012 / 2014$ & -0.625 & & \\
& $(0.569)$ & 58 & 60 \\
$2012 / 2015$ & {$[0.275]$} & & \\
& $-2.577^{* *}$ & & \\
& $(1.298)$ & & \\
& {$[0.050]$} & & \\
\end{tabular}

GHG emissions are averaged over 3-year periods for 2013-2015. Emissions differences between two years or period 0 and 1 are defined as $\ln (G H G 1+1)-\ln (G H G 0+1)$. The OLS estimates control for historic GHG emissions in 2012 (in log) and NAICS code indicator variables.

$* * *$ is significant at the $1 \%$ level; $* *$ significant at the $5 \%$ level; $*$ significant at the $10 \%$ level. Robust standard errors are reported in parentheses, and $\mathrm{p}$ values are given in square brackets.

much larger than for the effects reported in Table 3 , is certainly explained by the difference in the average of emissions between the treatment and comparison groups, as described above. Taking this size effect into account, the negative and significant sign of the estimated parameter tends nonetheless to confirm the previous results.

\section{Conclusion and policy implications}

This article evaluates the impact of the Québec ETS on the performance of regulated industrial facilities and reveals its effectiveness at reducing GHG emissions. But the mechanism's adverse impact on facilities' economic performance raises important questions for policymakers, particularly with Canada's commitment to the Paris Climate Agreement and with each province's and territory's obligation to devise a carbon pricing strategy in 2018.

Contrary to what was observed in the majority of studies on the EU ETS [e.g. 8, 18, 19, 31], Québec's carbon market had a negative impact on employment in regulated facilities. This suggests that these facilities also reduced operations, rather than only improving production processes, through innovation for instance. This contrasts with previous studies that have evidenced the greater role played by innovation in Europe [16, 17, 20]. The overabundance of emissions permits during the first phase and their low price ceiling could have contributed to this outcome in Québec. The price ceiling established in 2013 (CAD \$10.75) might not be enough to encourage the adoption of new technologies once the facilities' abatement cost for emissions is taken into account. Further studies would be justified to see whether this low-technology adoption pattern persists despite carbon price increases. Yamazaki [46] observes a similar pattern in British Columbia for the period 2008-2013 that precedes and corresponds to the launch of the carbon tax. The tax had a significant negative impact on employment for the facilities pertaining to the same subset of sectors considered in this study.

It would be interesting in future research to investigate the factors that might explain the negative employment effect characterizing the early implementation stage of carbon pricing policies in $\mathrm{BC}$ and QC. Explanations might be found in carbon leakage and/or the closure of large polluting facilities. Another explanation could be a spillover effect within firms and between facilities, if firms have relocated emissions internally from regulated plants to non-regulated ones. These effects raise, once again, questions about the lack of coordination and/or harmonization of climate and carbon pricing policies in Canada and worldwide [29].

Another explanation may be uncertainty concerning the future of regulation and carbon pricing. For example, in September 2017, Ontario signed a cap-and-trade linking agreement with Québec and California, and announced that the ETS would become effective on January 1, 2018. On July 3, 2018, the regulation was cancelled and allowance trading prohibited in Ontario. ${ }^{9}$

Improving energy and carbon efficiency and developing and installing cleaner production technologies are long-run investments. They are costly in the short run, and only profitable after a few years, as long as the carbon price is high enough. If firms predict that the regulation could be removed in the future, and/or if they anticipate a low carbon price, they will choose the cheapest and most flexible compliance strategy. In order to avoid sunk costs, they will adapt their production levels in order to abate emissions.

To avoid this, public authorities should send clear signals that the regulation will be maintained in the long run and that carbon prices will be high enough. Such signals are necessary to induce polluting firms to set accurate expectations and choose the most economically efficient adaptation strategy, individually as well as collectively [29]. In addition, authorities may announce that the carbon price will rise gradually, in order to ensure that firms will have time to adapt.

This study has limits that also justify further research. First, it does not assess the QC ETS's overall net employment effect on the entire 
economy. Research on BC has shown that a carbon tax accompanied by green fiscal reform could have an overall positive effect on employment [46]. ${ }^{10}$ Such an outcome is possible with an ETS, as long as all the permits are sold and the revenue collected is used to cut preexisting fiscal distortions, such as personal and/or corporate income taxes [49]. ${ }^{11}$ This solution was not adopted in the case of the QC ETS; only a part of the permits were sold by 2017, and the revenue was allocated to the Québec Green Fund [11].

In Ontario, the cap-and-trade system has been canceled for political and electoral reasons, and to satisfy the electorate's opposition to rising fossil fuel prices. ${ }^{12}$ The fall 2018 street protests against rising carbon taxes on diesel in France echoed events in Ontario. These examples illustrate a common reaction to rising carbon prices, and they should remind environmental policymakers to account for and smooth the social consequences of their policy. Indeed, carbon price regulations are regressive, as they exacerbate income and wealth inequalities [29]. This is mainly due to the fact that energy commands a relatively larger share in the living standard of the poorest quartiles of the population. This justifies using part of the revenue of a carbon price regulation in order to compensate the categories of people that are vulnerable to rising carbon prices.

In the coming years, it will be important to examine how the revenues generated by the QC ETS (CAD \$3 billion by 2020) are used and whether public investments in green and renewable technologies could compensate for the employment losses observed in large industrial polluters. For instance, the Sustainable Development Commissioner of Québec has already challenged the effectiveness of the QC Green Fund and the programs it finances, as well as their governance and monitoring [12].

A second limitation of this study consists in the variables used to measure economic performance. It was impossible for us to assess the impact of the QC ETS on the carbon intensity of production (emissions divided by output). Data on production are common at the firm level, but seldom available at the disaggregated facility level of this study. An avenue for future research would be to develop further indicators for measuring the QC ETS's economic impact on industrial facilities, in particular related to carbon intensity of production, environmental innovation and technologies, and to collect the data through surveys.

\section{Notes}

1. See for instance Chan et al. [7], Marin et al. [8] and Yang et al. [9] for detailed presentations of the underlying mechanisms at stake. The carbon leakage mechanism can occur in this case, as Quebec is a relatively small jurisdiction in a context of free trade and competition, and as its decision to implement carbon regulation unilaterally is likely to leave world market conditions (price, demand, supply) unchanged [10].

2. See Brohé and Burniaux [21] and Gollier and Tirole [29] for more detailed explanations on the rationality behind the decision to cut pollution, and for the definition of the MACs function.

3. Scaling down activity as a strategy for reducing emissions has been observed in the US, following the launch of the $\mathrm{SO}_{2}$ ETS in 1993. This scheme hastened the shutdown of old and dirty coal-fired power utilities [30].

4. According to the Government of Québec's definition of GHG emissions, "GHG means one or more of the gases listed in the second paragraph of section 46.1 of the Environment Quality Act, namely carbon dioxide $\left(\mathrm{CO}_{2}\right)$, methane $\left(\mathrm{CH}_{4}\right)$, nitrous oxide $\left(\mathrm{N}_{2} \mathrm{O}\right)$, hydrofluorocarbons (HFCs), perfluorocarbons (PFCs) and sulfur hexafluoride (SF6), as well as nitrogen trifluoride (NF3)" [35]. All these GHG gases are measured in $\mathrm{CO}_{2}$ equivalent $\left(\mathrm{CO}_{2} \mathrm{e}\right)$.

5. The choice of the number of neighbors for the NNM procedure requires a tradeoff. On the one hand, a one-to-one NNM lowers the standard deviations of the estimates compared to an NNM procedure employing more than one neighbor, and also compared to linear regressions [42]. Matching with more than one neighbor is also justified when the comparison group is larger than the treatment group, as there may exist, for each observation in the treatment, more than one good match in the comparison group. In addition, matching a treatment group with a larger comparison group enables the averaging out of idiosyncratic shock [40]. On the other hand, increasing the number of neighbors in the NNM procedure introduces a bias in the estimates, as the second and third best neighbors are necessarily worse than the first best in terms of matching [42]. A facility in the comparison group can be used more than once as a match, which is NNM with replacement [17], and likely to occur when matching is specified on three neighbors and/ or there is a relatively limited number of control facilities in a sub-sector.

6. In 2007, Alberta implemented a carbon pricing scheme (SGER) for large industrial emitters (over 100,000 t $\mathrm{CO}_{2}$ /year) with an effective average carbon price between $C A D \$ 1.8$ and $\mathrm{CAD} \$ 5 / \mathrm{t} \quad \mathrm{CO}_{2} \mathrm{e}$, considered to be too low to 
induce firms to cut their emissions [44]. Québec has also implemented a carbon tax on energy producers since October 2007 [45]. But its low level - CAD $\$ 3.5 / \mathrm{t} \quad \mathrm{CO}_{2}$ - made it ineffective [46].

7. The data set is therefore composed of facilities with emissions exceeding 50,000 $\mathrm{t} \mathrm{CO}_{2} \mathrm{e}$. A facility remains in the data set, and in the GHGRP, even if its emissions fall below that threshold afterward.

8. See note 2 .

9. See [52].

10. In the revenue-neutral carbon tax program implemented in BC in 2008, the tax is paid by a subset of sectors (industry), and the money collected is redistributed to all sectors, including services such as insurance, banking, health and the economy, through reductions in personal and corporate income taxes and lump-sum transfers to low-income households. Disentangling Yamazaki [46], it appears that the employment effect is negative on the subset of regulated sectors, positive for non-regulated sectors and positive for the entire economy.

11. Note that tradable permits have usually been granted for free during the early stages of ETS (e.g. the US $\mathrm{SO}_{2}$ market launched in 1993; the European carbon market launched in 2005) in order to ensure the political acceptability of the new environmental policy [50] and/or as a response to industrial lobbying [51].

12. See note 5 .

\section{Disclosure statement}

No potential conflict of interest was reported by the authors.

\section{ORCID identifier}

Julien Hanoteau: https://orcid.org/0000-0003-2951-9466

\section{References}

[1] Environment Canada. A climate change plan for the purposes of the Kyoto protocol implementation act; 2012a. Available from http://publications.gc.ca/collections/collection_2012/ec/En11-11-2012-eng.pdf (accessed 20 December 2017).

[2] Environment Canada. Statement by minister Kent; 2012b. Available from http://ec.gc.ca/default.asp?lang= $E n \& n=976258 C 6-1 \&$ news $=6$ B04014B-54FC-4739-B22CF9CD9A840800 (accessed 20 December 2017).

[3] MDDELCC. Carbon market in North America; 2011. Available from http://www.mddelcc.gouv.qc.ca/communiques_en/2011/c20111215-carbonmarket.htm (accessed 1 June 2018).

[4] MDDELCC. Strengths and advantages of Québec's cap-and-trade system. Québec City (QC): Gouvernement du Québec; 2018.

[5] Francoeur L-G. GES: Québec impose des plafonds. Le Devoir. 2011 December 16;A1.
[6] Sansfaçon J-R. Marché du carbone-cap sur les résultats. Le Devoir. 2011 December 17;B4.

[7] Chan HS, Li S, Zhang F. Firm competitiveness and the European Union emissions trading scheme. Energy Policy. 2013;63:1056-1064. doi:10.1016/ j.enpol.2013.09.032.

[8] Marin G, Marino M, Pellegrin C. The impact of the European emissions trading scheme on multiple measures of economic performance. Environ Res Econ. 2017;3:1-32.

[9] Yang L, Li F, Zhang X. Chinese companies' awareness and perceptions of the emissions trading scheme (ETS): evidence from a national survey in China. Energy Policy. 2016;98:254-265. doi:10.1016/ j.enpol.2016.08.039.

[10] Copeland BR, Taylor MS. Trade and the environment: Theory and evidence. Princeton (NJ): Princeton University Press; 2013.

[11] MDDELCC. Bilan mi-parcours du Plan d'action 20132020 sur les changements climatiques. Québec City (QC): Gouvernement du Québec; 2017.

[12] Sustainable Development Commissioner. 2016. Carbon market: description and issues. Report of the Sustainable Development Commissioner, Québec. http://www.vgq.gouv.qc.ca/en/en_publications/en_rapport-annuel/en_fichiers/en_Rapport2016-2017-CDD.pdf

[13] MDDELCC. Cible de réduction d'émissions de gaz à effet de serre du Québec pour 2030 - document de consultation. Québec City (QC): Gouvernement du Québec; 2015.

[14] Martin G, Saikawa E. Effectiveness of state climate and energy policies in reducing power-sector $\mathrm{CO} 2$ emissions. Nat Clim Change. 2017;7:912-919. doi: 10.1038/s41558-017-0.

[15] Sousa R, Aguiar-Conraria L. Energy and carbon prices: a comparison of interactions in the European Union emissions trading scheme and the Western climate initiative market. Carbon Manage. 2015;6: 129-140. doi:10.1080/17583004.2015.1097007.

[16] Martin R, Muûls M, Wagner UJ. The impact of the European Union emissions trading scheme on regulated firms: what is the evidence after ten years? Rev Environ Econ Policy. 2016;10:129-148. doi: 10.1093/reep/rev016.

[17] Petrick S, Wagner U. 2014. The impact of carbon trading on industry: Evidence from German manufacturing firms (Kiel Working Paper No. 1912), Kiel Institute for the World Economy (IfW)Kiel, Germany.

[18] Anger N, Oberndorfer U. Firm performance and employment in the EU emissions trading scheme: an empirical assessment for Germany. Energy Policy. 2008;36:12-22. doi:10.1016/j.enpol.2007.09.007.

[19] Commins N, Lyons S, Schiffbauer M, et al. Climate policy \& corporate behavior. Energy J. 2011;32:51-68.

[20] Wagner UJ, Muûls M, Martin R, et al. 2013. An evaluation of the impact of the EU emissions trading system on the industrial sector. Plant-level evidence from France. Paper presented at the AERE Conference, Banff, Canada.

[21] Brohé A, Burniaux S. The impact of the EU ETS on firms' investment decisions: evidence from a survey. 
Carbon Manage. 2015;6:221-231. doi:10.1080/ 17583004.2015 .1131384$.

[22] Löfgren $\AA$, Wråke $M$, Hagberg $T$, et al. Why the EU ETS needs reforming: an empirical analysis of the impact on company investments. Clim Policy. 2014; 14:537-558. doi:10.1080/14693062.2014.864800.

[23] Sandoff A, Schaad G. Does EU ETS lead to emission reductions through trade? the case of the Swedish emissions trading sector participants. Energy Policy. 2009;37:3967-3977. doi:10.1016/j.enpol.2009.04.043.

[24] Martin R, Muûls M, de Preux LB, et al. Industry compensation under relocation risk: a firm-level analysis of the EU emissions trading scheme. Am Econ Rev. 2014a;104:2482-2508.

[25] Martin R, Muûls M, de Preux LB, et al. On the empirical content of carbon leakage criteria in the EU emissions trading scheme. Ecol Econ. 2014b;105:78-88.

[26] Kolk A, Levy D. Winds of change: corporate strategy, climate change and oil multinationals. Eur Manag J. 2001;19:501-509. doi:10.1016/S-2373(01)00064-0.

[27] Levy D. Oceans apart? business responses to global environmental issues in Europe and the United States. Environ Sci Policy Sust Dev. 2000;42:8-21. doi:10.1080/00139150009605761.

[28] Talbot D, Boiral O. Can we trust corporates GHG inventories? an investigation among Canada's large final emitters. Energy Policy. 2013;63:1075-1085. doi: 10.1016/j.enpol.2013.09.054.

[29] Gollier C, Tirole J. Negotiating effective institutions against climate change. In: Cramton P, MacKay DJ, Ockenfels $\mathrm{A}$, et al., editors. Global carbon pricing: the path to climate cooperation. Cambridge (MA): MIT Press; 2017. p. 165-205.

[30] Joskow PL, Schmalensee R. The political economy of market-based environmental policy: the US acid rain program. J Law Econ. 1998;41:37-84. doi:10.1086/ 467384.

[31] Calel R, Dechezlepretre A. Environmental policy and directed technological change: evidence from the European carbon market. Rev Econ Stat. 2016;98: 173-191. doi:10.1162/REST_00470.

[32] MDDELCC. Québec's cap-and-trade system-technical overview. Québec City (QC): Gouvernement du Québec; 2014.

[33] Gouvernement du Québec. Climate change action; plan 2013--2020. Québec City (QC): Government of Québec; 2012a.

[34] ÉcoRessources. Estimation des retombées économiques des plans d'action 2006-2012 et 20132020 sur les changements économiques. Québec City (QC): ÉcoRessources; 2015.

[35] Gouvernement du Québec. Regulation respecting a cap-and-trade system for greenhouse gas emission allowances. chapter Q-2, r. 46.1; 2012c, Gouvernement du QuébecQuébec, Canada .

[36] [Gouvernement du Québec. Determination of annual caps on greenhouse gas emission units relating to the cap-and-trade system for greenhouse gas emission allowances for the 2013-2020 period. Gaz Off Québec. 2012b;144:3612.
[37] Grubb M, Neuhoff K. Allocation and competitiveness in the EU emissions trading scheme: policy overview. Clim Policy. 2006;6:7-30. doi:10.3763/cpol.2006.0602.

[38] Pearse R, Böhm S. Ten reasons why carbon markets will not bring about radical emissions reduction. Carbon Manage. 2014;5:325-337. doi:10.1080/17583004. 2014.990679.

[39] Wood PJ, Jotzo F. Price floors for emissions trading. Energy Policy. 2011;39:1746-1753. doi:10.1016/ j.enpol.2011.01.004.

[40] Fowlie M, Holland SP, Mansur ET. What do emissions markets deliver and to whom? evidence from Southern California's NOx trading program. Am Econ Rev. 2012;102:965-993.

[41] Heckman JJ, Ichimura H, Todd PE. Matching as an econometric evaluation estimator: evidence from evaluating a job training programme. Rev Econ Stud. 1997;64:605-654. doi:10.2307/2971733.

[42] Stuart EA. Matching methods for causal inference: a review and a look forward. Statist Sci. 2010;25:1-29. doi:10.1214/09-STS313.

[43] Abadie A, Imbens GW. Large sample properties of matching estimators for average treatment effects. Econometrica. 2006;74:235-267. doi:10.1111/j.14680262.2006.00655.x.

[44] Leach A. Policy forum: Alberta's specified gas emitters regulation. Canadian Tax J. 2012;60:881-898.

[45] CBC. Québec to collect nation's 1st carbon tax; 2007. Available from http://www.cbc.ca/news/canada/ montreal/Québec-to-collect-nation-s-1st-carbon-tax1.684888 (accessed 20 December 2017).

[46] Yamazaki A. Jobs and climate policy: evidence from British Columbia's revenue-neutral carbon tax. J Environ Econ Manage. 2017;83:197-216. doi: 10.1016/j.jeem.2017.03.003.

[47] Environment and Climate Change Canada (ECCC). Pan-Canadian framework on clean growth and climate change: Canada's plan to address climate change and grow the economy. Gatineau (QC): Environment and Climate Change Canada; 2017.

[48] Wagner UJ, Muûls M, Martin R, et al. 2014. The causal effects of the European Union Emissions Trading Scheme: evidence from French manufacturing plants. Paper presented at Fifth World Congress of Environmental and Resources Economists, Instanbul, Turkey.

[49] Cramton P, Kerr S. Tradeable carbon permit auctions: how and why to auction not grandfather. Energy Policy. 2002;30:333-345. doi:10.1016/S-4215(01)00100-8.

[50] Stavins RN. What can we learn from the grand policy experiment? lessons from SO2 allowance trading. J Econ Persp. 1998;12:69-88. doi:10.1257/jep.12.3.69.

[51] Hanoteau J. Lobbying for carbon permits in Europe. Louvain Econ Rev. 2014;80:61-87. doi:10.3917/ rel.801.0061.

[52] Ministry of the Environment, Conservation and Parks. Ontario Introduces Legislation to End Cap and Trade Carbon Tax Era in Ontario. News Realease. 2018 July 25. Available from: https://news.ontario.ca/ ene/en/2018/07/ontario-introduces-legislation-to-endcap-and-trade-carbon-tax-era-in-ontario.html 